\title{
Efficacy of a Novel Medical Adhesive for Sealing Lung Parenchyma: An in vitro Study in Rabbit Lungs
}

\author{
Sebastian Kalverkamp ${ }^{a} \quad$ Anna Mantas $^{a} \quad$ Jan Spillner ${ }^{a} \quad$ Flutura Hima $^{a}$ \\ Stephanie Sarah Kanzler ${ }^{b}$ Thaddäus Stopinskic René H. Tolba ${ }^{c}$ Rashad Zayat ${ }^{a}$ \\ aDepartment of Thoracic and Cardiovascular Surgery, University Hospital RWTH Aachen, Aachen, Germany; \\ ${ }^{b}$ Adhesys Medical GmbH, Aachen, Germany; 'Institute for Laboratory Animal Science \& Experimental Surgery, RWTH \\ Aachen, University Hospital RWTH Aachen, Aachen, Germany
}

\section{Keywords}

Bronchopleural fistula · Air leak · Thoracic surgery · Lung resection · Perioperative management · Sealant glue $\cdot$ In vitro

\begin{abstract}
Introduction: During thoracic resection procedures, complete hemostasis and aerostasis are priorities. A persistent alveolar air leak is associated with increased morbidity and mortality rates. This study aimed to evaluate whether the novel medical adhesive VIVO (Adhesys Medical $\mathrm{GmbH}$ Aachen, Germany) is a reliable alternative sealing technique to routine surgical procedures. Methods: We conducted an in vitro animal study by analyzing 21 lungs of New Zealand $(n=19)$ and Chinchilla Bastard $(n=2)$ rabbits (age, 11-18 weeks; weight, 2,400-3,600 g). Three groups, each comprising 7 animals, were evaluated. VIVO (VIVO-group) was compared with standard surgical lung parenchymal lesion closure with a polypropylene suture (Suture-group) and TachoSil ${ }^{\circledR}$ (TachoSil-group). We adopted a stable, pressurecontrolled ventilation protocol. After explantation, a surgical incision $0.5-\mathrm{cm}$ deep and $1.5-\mathrm{cm}$ wide was made in the
\end{abstract}

lungs using a customized template. Air leak was measured quantitatively $(\mathrm{mL} / \mathrm{min})$ using a respirator and visualized qualitatively by 2 observers who made independent judgments. Next, the leak was closed using VIVO, suture, or TachoSil $^{\circledR}$ as specified by the manufacturer. Subsequently, positive end-expiratory pressure (PEEP) and inspiratory pressure were gradually increased until a maximum of 15 and 30 mbar were attained, respectively. Results: At PEEPs of 8,10 , and 15 mbar, VIVO achieved complete sealing of the profound parenchymal defect in all $(n=7)$ lungs. After closure of the incision, we observed an air leak variation of 127 $\pm 114 \mathrm{~mL} / \mathrm{min}$ (Suture-group), $31 \pm 49 \mathrm{~mL} / \mathrm{min}$ (VIVO-group), and $114 \pm 134 \mathrm{~mL} / \mathrm{min}$ (TachoSil-group). VIVO showed a significantly lower air leak than surgical sutures $(p=0.031)$ and TachoSil $^{\circledR}(p=0.046)$. Conclusion: VIVO offers sufficient closure of the lung parenchymal lesions. The novel adhesive enabled significantly better sealing with lower persistent air leakage than TachoSil ${ }^{\circledR}$ or surgical sutures. Further investigation using in vivo models is strongly encouraged to confirm our findings.

(c) 2021 S. Karger AG, Basel karger@karger.com www.karger.com/esr

(C) 2021 S. Karger AG, Base

Karger"
Correspondence to:

Sebastian

Kalverkamp, skalverkamp@ukaachen.de 


\section{Introduction}

Alveolar air leaks (AAL) represent a common postoperative complication after thoracic surgery procedures including lung parenchymal resection, such as lobectomy, atypical lung resection, and pleural decortication $[1,2]$. Lung parenchymal defects often lead to persistent air leaks requiring further interventions [2]. Many factors have been suggested as risk factors for the increased incidence of AAL after lung surgery, for example, patient-related factors such as emphysema and applied surgical techniques [3]. The prevention and management of air leaks are crucial for thoracic surgeons as well as patients [4]. Regardless of the type of surgical resection, ensuring uneventful tissue recovery is important because AAL is associated with high morbidity and mortality rates, prolonged hospital stay, high costs, and decreased quality of life for patients $[2,5]$.

Several approaches for managing AAL have been introduced. Commonly used surgical techniques are suturing or stapling, but both approaches may further damage the lung parenchyma [6]. Additional methods, including the application of sealants such as collagen-coated patches, fibrin glue, and other synthetic materials, have been used to minimize air leak severity and duration $[6,7]$. Sealants based on a fixed combination of a collagen patch coated with human thrombin-fibrinogen sponge-like TachoSil $^{\circledR}$ (Takeda, Osaka, Japan) have also been used [8, 9]. However, results from studies comparing TachoSil ${ }^{\circledR}$ with classical surgical techniques have not demonstrated additional value when using the sealant if airtightness was established with conventional practices $[6,8]$. In this study, we evaluated the efficacy of the novel polyurethane/urea technology-based medical adhesive VIVO (Adhesys Medical GmbH, Aachen, Germany) and compared it with TachoSil ${ }^{\circledR}$ and standard surgical sutures.

\section{Materials and Methods}

\section{Animals}

Twenty-one lungs from female New Zealand $(n=19)$ and Chinchilla Bastard $(n=2)$ rabbits (age, $11-18$ weeks and weight, 2,400-3,600 g) were included in this study. All experiments were conducted following German Federal Law regarding the protection of animals and DIRECTIVE 2010/63/EU on the protection of animals used for scientific purposes. The experiments were conducted in the Institute of Laboratory Animal Science at the University Hospital Aachen according to the 3 Rs Principle of Russell and Burch (i.e., replacement, reduction, and refinement). All organs were harvested from animals that were primarily used for other approved experiments, which did not harm the lungs; consequently, additional ethical approval for these experiments was not necessary.

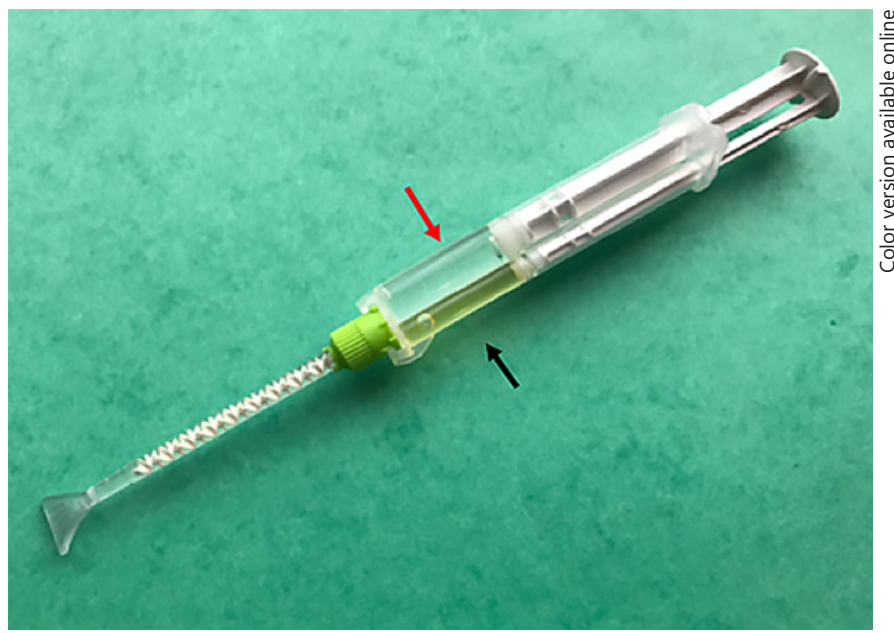

Fig. 1. The novel medical adhesive VIVO. VIVO consists of 2 components: an isocyanate-functionalized prepolymer as the main agent (red arrow) and a mixture of an amine-functionalized aspartic acid ester with a polyethylene glycol as a curing agent (black arrow).

\section{Novel Medical Adhesive}

Recent studies have reported the use of the novel medical adhesive VIVO based on polyurethane/urea technology [10, 11]. VIVO is composed of 2 ingredients: an isocyanate-functionalized prepolymer as an adhesive agent and a curing agent mixture mainly based on amine-functionalized aspartic acid ester(s) and filling agent(s) (Fig. 1) [10-12]. A static mixing unit was used to mix the 2 components, which could easily be applied to the wound surface. The hardening process begins after mixing, and complete curing is achieved in approximately $1.5 \mathrm{~min}$. The wound surface remains visible due to the transparent color. The VIVO syringe was prepared as follows: a double-chamber syringe was added to its tip in a vertical position for approximately $20 \mathrm{~s}$ to obtain bubble-free glue [10-12].

\section{Experimental Protocol}

Initially, we adopted a stable, pressure-controlled ventilation protocol using pilot pretests that ensured a physiological ventilation pattern and was adapted to small rabbit lungs [13]. The lungs were harvested after euthanizing the rabbits with an intravenous injection of $3 \mathrm{~mL}$ of Narcoren ${ }^{\circledR}$ (16 g/100 mL of pentobarbital sodium) into the marginal auricular vein [14]. A tracheal tube (Rüsch ${ }^{\circledR}$ endotracheal tube; inner diameter, $2.5 \mathrm{~mm}$; length, $140 \mathrm{~mm}$ ) was inserted into the trachea and cuffed and fixated with a ligature. The tube was connected to a ventilator (EVITA4 NeoFlow ${ }^{\mathrm{TM}}$; Dräger ${ }^{\circledR}$, Lübeck, Germany; Fig. 2a). The lungs were ventilated with a positive end-expiratory pressure (PEEP) of 5 mbar, inspiratory pressure $\left(\mathrm{P}_{\text {insp }}\right)$ of 18 mbar, $21 \% \mathrm{O}_{2}$, respiratory rate of $40 / \mathrm{min}$, inspiration/expiration ratio of $1: 1$, and inspiratory time of $0.5 \mathrm{~s}$.

After explantation, the lungs were macroscopically examined for air leaks, followed by a precisely defined surgical incision that was 0.5 -cm deep and 2-cm wide. We customized a 2-part incision template that enabled a standardized lesion (Fig. 2b). 
Fig. 2. Experimental setup. a The tracheas of a pair of rabbit lungs were intubated with an endotracheal tube (foreground) and connected to a ventilation machine (background). The lungs were inflated. b The customized 2-part incision template allowed a standardized lesion of the lung tissue.
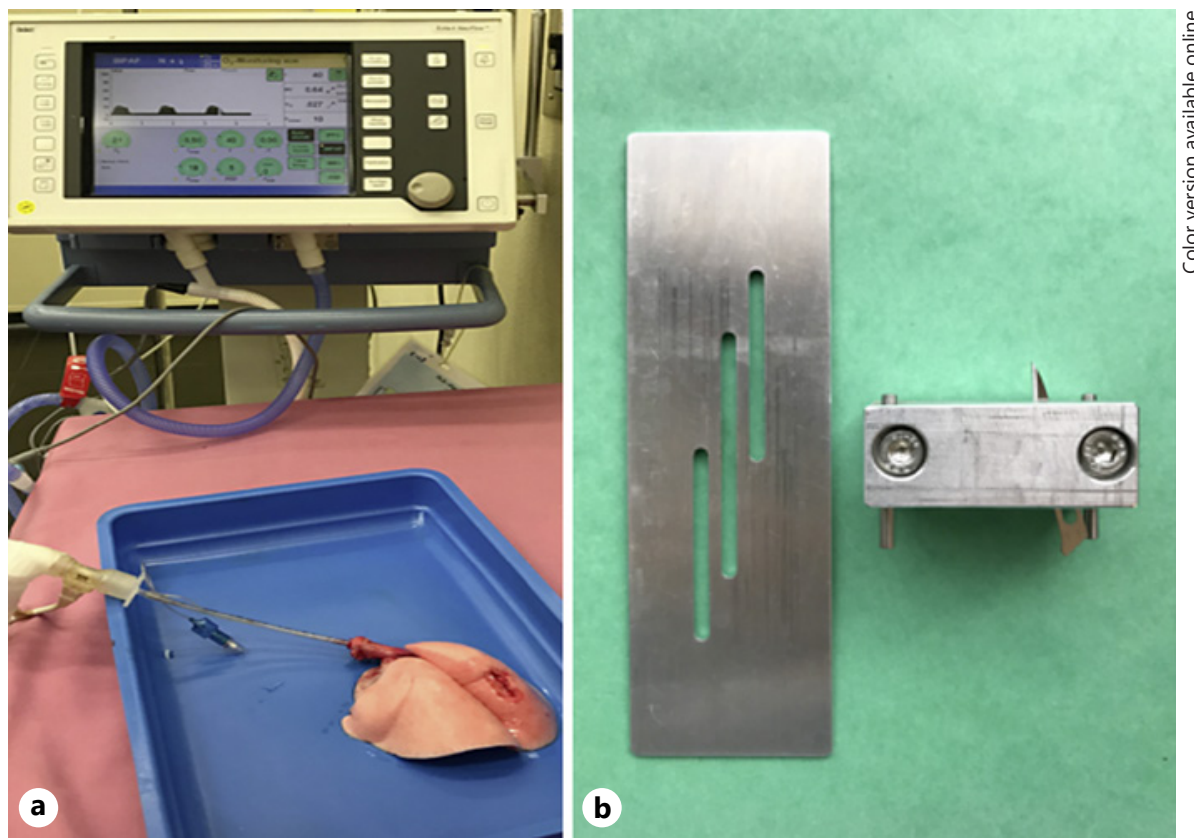

Air leakages were identified by visualizing the ascending bubbles, which was confirmed by 2 observers who made independent judgments. The lesion and remaining parts of the lungs were sprinkled with water to observe potential bubbles that indicated leakage. In addition, air leakage was registered on the respirator as a ventilation mismatch $\left(M V_{\text {leck }}\right)$. $M V_{\text {leck }}$ resulted in a difference between inspiratory and expiratory minute volumes $\left(\mathrm{MV}_{\mathrm{i}}\right.$ and $M \mathrm{~V}_{\mathrm{e}}$, respectively). MV was computed using the recorded inspiratory and expiratory tidal volumes.

At the beginning of ventilation, the respirator noted a minor air leak in 20 of 21 lungs, although the explantation proceeded with no macroscopic damage. This appeared to be an in-built leakage of the ventilation machine. For further analysis, all baseline leakages were reset to $0 \mathrm{~mL} / \mathrm{min}$, and the baseline number was subtracted from the subsequent leakages.

Then, the lesion was treated with VIVO (VIVO-group), surgical suture (Suture-group), or TachoSil ${ }^{\circledR}$ (TachoSil-group), as specified by the manufacturers' instructions (Fig. 3). Each group comprised 7 rabbit lungs. During treatment with the sealants, the lungs were disconnected from the ventilation machine. Then, the sealant was applied onto the defect. After $90 \mathrm{~s}$, VIVO was completely polymerized and ventilation was restarted. For the surgical suture, 2 -row stitches were performed. TachoSil ${ }^{\circledR}$ was applied to the lesion site. Mild compression was applied for $3.5 \mathrm{~min}$ before ventilation was restarted.

Ventilation was started at a PEEP of 5 mbar and $\mathrm{P}_{\text {insp }}$ of 18 mbar, and both parameters were gradually increased until a maximum PEEP of 15 mbar and $P_{\text {insp }}$ of 30 mbar were achieved. Then, both parameters were decreased again to the baseline values. Following each increase in PEEP and Pinsp at intervals of $2 \mathrm{~min}, \mathrm{MV}$ leck, MVi, MVe, and observations such as burst pressure were recorded. Similar burst pressures indicated comparability of the lungs and also enabled comparisons of the sealing methods.

\section{Histopathological Analysis}

Specimens containing the lesion site and untouched, normal lung parenchyma were resected and stored in $4 \%$ buffered formalin for histopathological examination. The specimens were trimmed, fixated in formalin, and processed through a vacuum infiltration processor. Finally, hematoxylin-eosin staining was performed. The tested lungs were then disposed from the Institute of Laboratory Animal Science at the University Hospital Aachen.

\section{Statistical Analysis}

All statistical analyses were performed using SPSS statistical software, version 25.0 (SPSS Inc., Chicago, IL, USA). We performed an a priori power analysis using $\mathrm{G}^{*}$ Power (version 3.1: tests for correlation and regression analyses) with an alpha of 0.05 and a power of 0.80 , and the required sample size was 21 ( 7 per group). Figures were constructed using GraphPad Prism version 7.0a for MAC OS X (GraphPad Software, La Jolla, CA, USA). Continuous variables were expressed as the mean \pm standard deviation. Categorical variables were expressed as absolute numbers and percentages. Continuous repeated variables were analyzed using 2 -way analysis of variance for between- and within-group comparisons. $p$ values were reported as three-digit numbers. A $p$ value of $<0.05$ was considered statistically significant.

\section{Results}

Organ retrieval and ventilation of the lungs were conducted successfully. The incision was repeated in a standardized manner using a customized template (Fig. 2b). Sealing of the incision was performed successfully in all lungs $(n=21)$. 

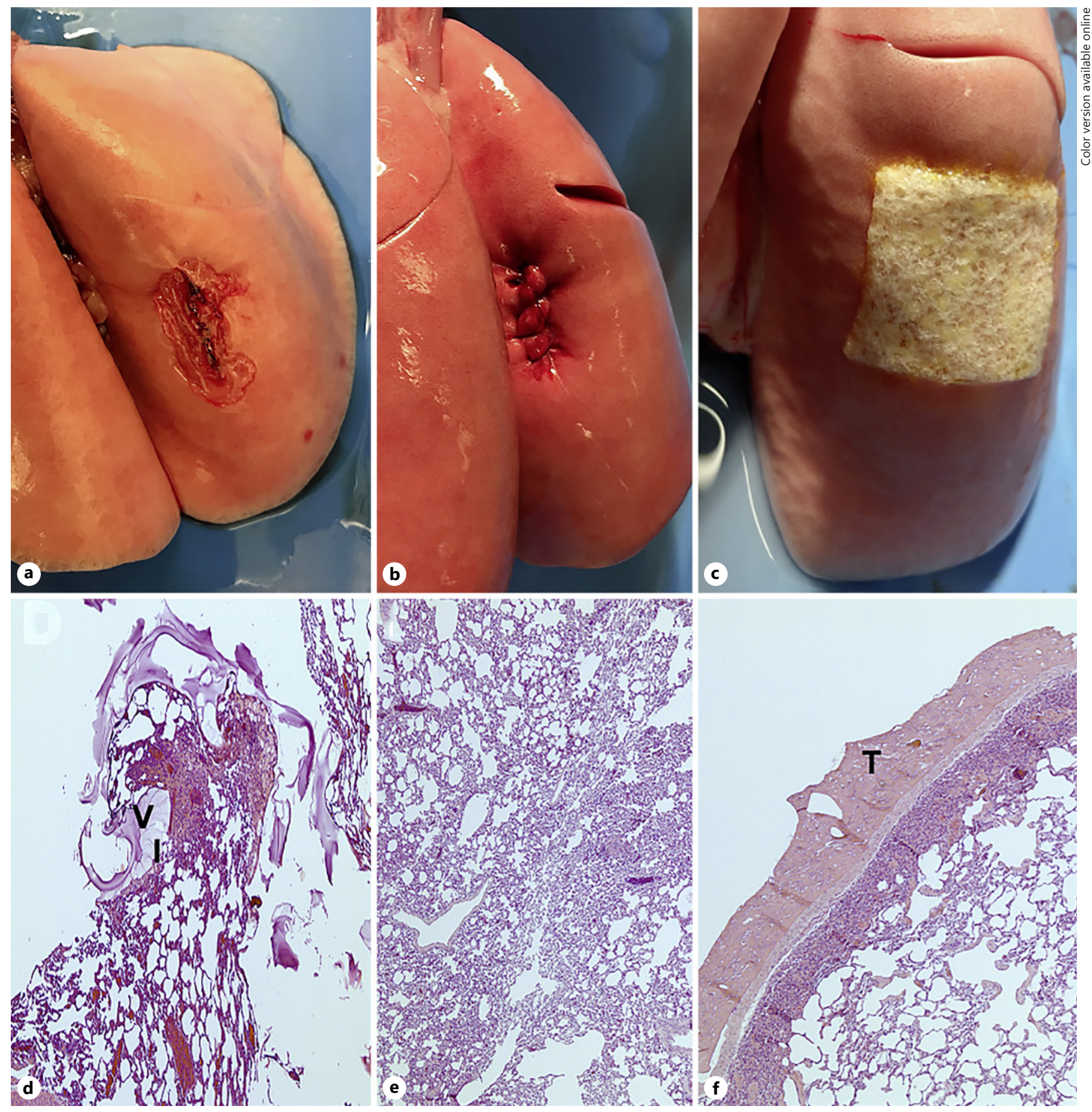

Fig. 3. Histopathological findings of the lung tissue treated with different sealants. a, b Macroscopic views of right lung parenchymal damage treated with VIVO (a), suture (b), and TachoSil ${ }^{\circledR}(\mathbf{c})$. $\mathbf{d}-\mathbf{f} \times 5$ magnification of histopathological slides of transverse lung tissue sections stained with H.E. The incision site (I) was closed by:
VIVO (V), which laid densely over the lung parenchyma and showed no disruption in continuity (d); The incision was sutured: No suture material in the slide is seen (e). However, alveoli of different sizes indicated localization of the suture. $\mathbf{f}$ Incision sealed with TachoSil ${ }^{\circledR}(\mathrm{T})$, which laid densely over the lung parenchyma. 
Fig. 4. Air leakages in all 3 groups throughout the experiment. MS, mean square; DF, degrees of freedom; SS, sum of squares; * suture versus VIVO $p<0.05$; ** suture versus VIVO $p<0.01$; ${ }^{\#}$ TachoSil ${ }^{\circledR}$ versus VIVO $p<0.05$.

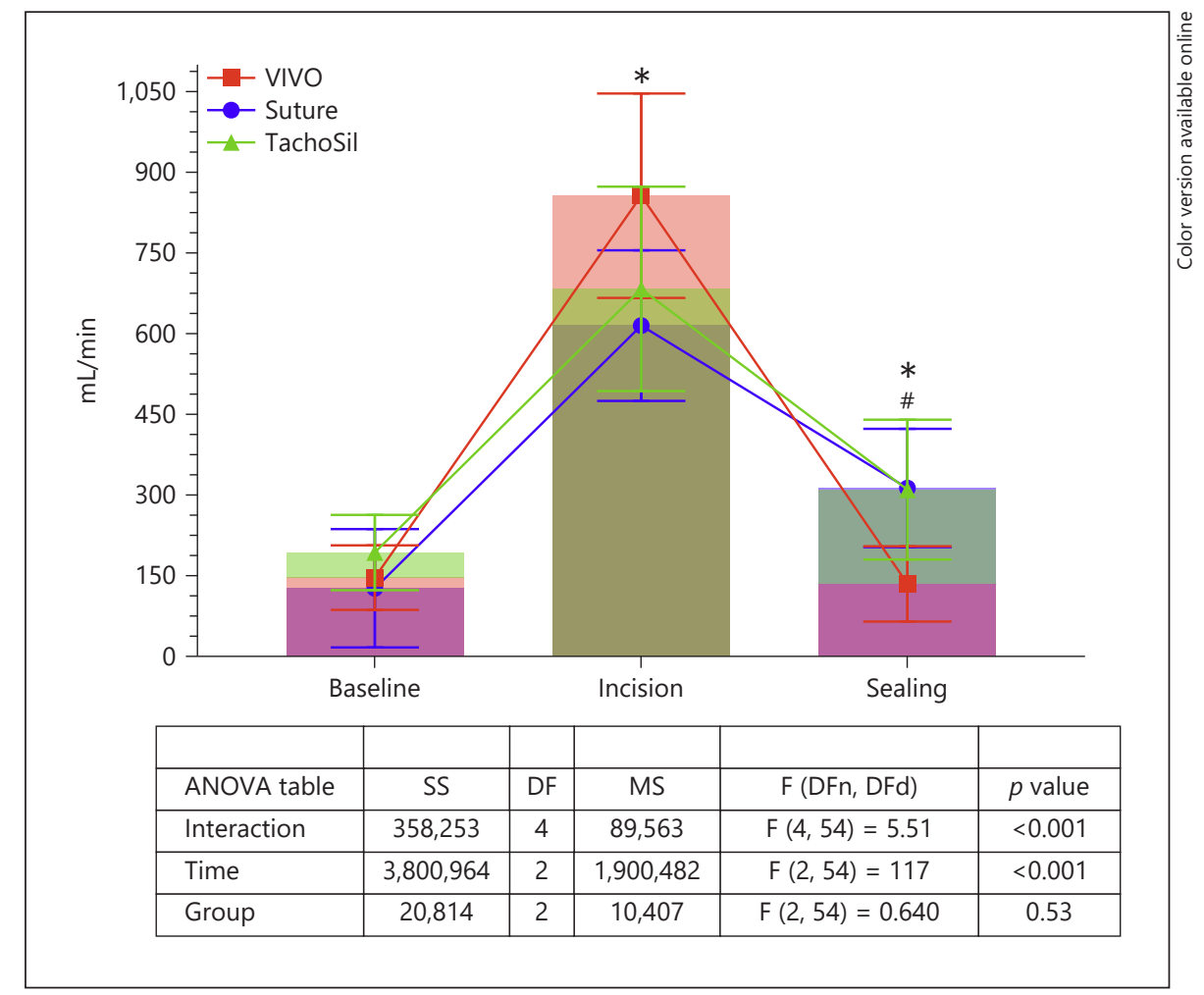

\section{Burst Pressures}

Table 1 presents an overview of the ventilation setting, under which, a burst pressure was achieved. With PEEP of 13-15 and $P_{\text {insp }}$ of 22-30 mbar, lung barotrauma was observed. In the Suture-group, burst pressure was detected at PEEP of 13 and $P_{\text {insp }}$ of 22 mbar in 1 of 7 lungs, PEEP of 15 and $P_{\text {insp }}$ of 22 mbar in 4 lungs, and PEEP of 15 and $\mathrm{P}_{\text {insp }}$ of $30 \mathrm{mbar}$ in 2 lungs. The burst pressure in the VIVO-group ranged from PEEP of 13 and $\mathrm{P}_{\text {insp }}$ of $22 \mathrm{mbar}$ in 1 of 7 lungs, $P E E P$ of 15 and $P_{\text {insp }}$ of 22 mbar in 3 lungs, PEEP of 15 and $P_{\text {insp }}$ of 25 mbar in 2 lungs, and PEEP of 15 and $P_{\text {insp }}$ of 30 mbar in 1 lung. The TachoSil-group showed burst pressures at PEEP of 15 and $\mathrm{P}_{\text {insp }} 22 \mathrm{mbar}$ in 4 of 7 lungs, PEEP of 15 and $\mathrm{P}_{\text {insp }}$ of 25 mbar in 2 lungs, and PEEP of 15 and $\mathrm{P}_{\text {insp }}$ of 30 mbar in 1 lung.

\section{Sealing Effects}

Table 2 shows the air leakage measured in the different groups. After sealing, leak variation was observed: $127 \pm$ $114 \mathrm{~mL} / \mathrm{min}$ (Suture-group), $31 \pm 49 \mathrm{~mL} / \mathrm{min}$ (VIVOgroup), and $114 \pm 134 \mathrm{~mL} / \mathrm{min}$ (TachoSil-group), as shown in Figure 4. With VIVO, a significantly lower residual air leak was achieved than with surgical closure $(p=0.031)$. We also detected a significantly lower air leak in the VIVO-group than in the TachoSil-group ( $p=$
Table 1. Ventilation setting for burst pressures of all lungs in each group

\begin{tabular}{llll}
\hline $\begin{array}{l}\text { Ventilation } \\
\text { protocol }\end{array}$ & $\begin{array}{l}\text { Suture } \\
\text { group, } \\
n(\%)\end{array}$ & $\begin{array}{l}\text { VIVO- } \\
\text { group, } \\
n(\%)\end{array}$ & $\begin{array}{l}\text { TachoSil- } \\
\text { group, } \\
n(\%)\end{array}$ \\
\hline PEEP 13, $\mathrm{P}_{\text {insp }} 22$ & $1(14.3)$ & $1(14.3)$ & 0 \\
PEEP 15, $\mathrm{P}_{\text {insp }} 22$ & $4(57.1)$ & $3(42.8)$ & $4(57.1)$ \\
PEEP 15, $\mathrm{P}_{\text {insp }} 25$ & 0 & $2(28.6)$ & $2(28.6)$ \\
PEEP 15, $\mathrm{P}_{\text {insp }} 30$ & $2(28.6)$ & $1(14.3)$ & $1(14.3)$ \\
\hline
\end{tabular}

PEEP, positive end-expiratory pressure in mbar; $\mathrm{P}_{\text {insp }}$, inspiratory pressure in mbar.

0.046). Histopathological findings of the lung tissue supplied with each sealant are presented in Figure 3.

\section{Discussion}

Optimal sealing can be obtained with a synthetic material, which avoids immunogenicity and the risk of disease transmission associated with human material-like fibrin or collagen products. In lung tissue, it allows expansion, 
Table 2. Comparison of air leakage between the 3 groups

\begin{tabular}{llllll}
\hline $\begin{array}{l}\text { Air leakage, } \\
\mathrm{mL} / \mathrm{min}\end{array}$ & Suture-group & $\begin{array}{l}p \text { values } \\
\text { VIVO versus } \\
\text { suture }\end{array}$ & VIVO-group & Tachosil-group & $\begin{array}{l}p \text { values } \\
\text { VIVO versus } \\
\text { Tachosil }\end{array}$ \\
\hline Baseline & $126 \pm 110$ & 0.899 & $146 \pm 60$ & $193 \pm 70$ & 0.877 \\
Incision & $615 \pm 140$ & 0.002 & $856 \pm 190$ & $683 \pm 190$ & 0.046 \\
Sealing & $313 \pm 110$ & 0.031 & $135 \pm 70$ & $310 \pm 130$ & 0.046 \\
\hline
\end{tabular}

which results in uniform surface loads on the lung and reduces the risk of secondary tearing of fragile tissue near a treated site.

Fibrin-based glues have no cellular toxicity and do not impede wound healing because they are biological and biocompatible [15]. Among the various sealant glues, fibrin-based glues have been used widely as the gold standard. Depending on the origin of the thrombin, immune reactions have been observed, which in some cases resulted in anaphylactic shock [16]. When obtained from human pooled blood, contamination, such as a parvovirus infection, is possible $[17,18]$. Fibrin-based adhesives mimic the coagulation cascade by reinforcing the polymerization process of fibrin [15]. Polyurethane-based adhesives react mainly with the amino groups of proteins in the tissue, which enables urea compounds to form adhesions $[10,19]$. Polyurethanes activate platelets, which promote blood clotting [11, 19]. Moreover, polyurethanes possess thrombogenic properties due to their hydrophobic character, which promotes protein adhesion and triggering of the coagulation cascade $[11,19]$.

The novel polyurethane-based adhesive VIVO has several advantages over fibrin-based glue in terms of safety, preparation, and preservation. Because polyurethane prepolymers are completely synthetic, they do not pose a risk of transmission of infectious diseases. In addition, VIVO can be stored at room temperature and processed quickly, whereas fibrin-based glue must be refrigerated and then defrosted and has a short shelf life after defrosting. The biocompatibility and safety of VIVO have been investigated, and it has been demonstrated to be noninferior to fibrin-based glue $[11,20]$.

Polymerization of VIVO (60-90 s) required less time than TachoSil ${ }^{\circledR}$ ( $3 \mathrm{~min}$ ) but necessitated almost as much application skill as that required for TachoSil ${ }^{\circledR}$ application. Additionally, VIVO can be applied precisely in small amounts using a needle tip.

In the present study, VIVO achieved better sealing with significantly lower residual air leaks than TachoSil ${ }^{\circledR}$.
Additionally, VIVO showed significantly ameliorated air leakage compared with a surgical suture.

In the present study, VIVO showed the greatest airtightness, which was confirmed through the visualized fistulas, which correlated with the ventilation mismatch values indicating a leak. Even in the region of high, nonphysiological ventilation pressures, VIVO sealed the inflicted injury. Interestingly, in that case, the lungs $(n=7)$ suffered barotrauma at another location (data not shown).

In our experiments, sealant techniques were used alone. Because it has been reported that a combination of a sealant with a sheet; for example, TachoSil ${ }^{\circledR}$, tends to be more efficient, it is possible to investigate the efficacy of VIVO in combination with a sheet and/or suture $[21,22]$.

\section{Limitations}

There are some limitations to this study. For the purpose of the experiments, the lungs were retrieved from young rabbits that resembled human neonates; therefore, translation into (adult) humans is limited. Our analysis was performed in an in vitro model. Consequently, we were not able to test the effectiveness of VIVO and its interaction with the circulating blood component when applied to the lung parenchyma. An in vivo model would enable further biocompatibility analysis, which is already being planned. TachoSil ${ }^{\circledR}$ was only applied to collapsed lungs even though the manufacturer suggests application on inflated lungs. Another limitation is the inability to provide observer blinding due to the obvious differences in the appearance of the product.

\section{Conclusion}

We demonstrated that VIVO is comparable to Tacho$\mathrm{Sil}^{\circledR}$ and offers sufficient closure of lung parenchymal lesions and might be an efficient adjunct in the treatment of air leaks during thoracic surgery. In the rabbit model, the novel sealant glue enabled significantly better sealing 
with lower residual air leakage than $\mathrm{TachoSil}^{\circledR}$ and a surgical suture. Further in vivo investigations are necessary to support the reproducibility of our results in humans.

\section{Statement of Ethics}

According to the Federal German Animal Protection law, this in vitro study was conducted according to the $3 \mathrm{R}$ Principle with lungs retrieved from other granted experimental procedures, so no further permission was needed.

\section{Conflict of Interest Statement}

S.S.K. is a part-time employee of Adhesys Medical GmbH, Aachen, Germany. R.H.T. was former Chief Medical Officer and Founder of Adhesys Medical GmbH. Currently, R.H.T. holds no share and has no affiliation to Adhesys Medical GmbH. All the authors have no conflicts of interest to declare.

\section{Funding Sources}

This study received no external funding and was performed by own departmental and institutional resources (Department of Thoracic and Cardiovascular Surgery and Institute for Laboratory Animal Science \& Experimental Surgery, RWTH University Aachen, University Hospital RWTH Aachen, Aachen, Germany).

\section{Author Contributions}

S.K. and A.M. wrote and drafted the manuscript. S.K., A.M., and F.H. performed the experiment. A.M. and R.Z. collected and analyzed the data. S.S.K. was involved in the provision of study materials. F.H., T.S., and S.S.K. were involved project administration, research activity planning, and co-ordination. J.S. and R.H.T. provided supervision and interpretation the data. J.S., S.K., and R.H.T. helped in the conception and design of the study. All the authors critically revised the manuscript for important intellectual content. All the authors approved the final version of the manuscript.

\section{References}

1 Kaiser LR, Bavaria JE. Complications of thoracoscopy. Ann Thorac Surg. 1993 Sep;56(3): $796-8$.

2 Floyd RD, Hollister WF, Sealy WC. Complications in 430 consecutive pulmonary resections for tuberculosis. Surg Gynecol Obstet. 1959 Oct; 109:467-72.

3 Lazarus DR, Casal RF. Persistent air leaks: a review with an emphasis on bronchoscopic management. J Thorac Dis. 2017 Nov; 9(11): 4660-70.

4 Abolhoda A, Liu D, Brooks A, Burt M. Prolonged air leak following radical upper lobectomy: an analysis of incidence and possible risk factors. Chest. 1998 Jun;113(6):1507-10.

5 Wood DE, Lauer LM, Layton A, Tong KB. Prolonged length of stay associated with air leak following pulmonary resection has a negative impact on hospital margin. Clinicoecon Outcomes Res. 2016;8:187-95.

6 Malapert G, Hanna HA, Pages PB, Bernard A. Surgical sealant for the prevention of prolonged air leak after lung resection: metaanalysis. Ann Thorac Surg. 2010;90(6):177985.

7 Mouritzen C, Drömer M, Keinecke HO. The effect of fibrin glueing to seal bronchial and alveolar leakages after pulmonary resections and decortications. Eur J Cardiothorac Surg. 1993;7(2):75-80.

8 Marta GM, Facciolo F, Ladegaard L, Dienemann H, Csekeo A, Rea F, et al. Efficacy and safety of TachoSil ${ }^{\oplus}$ versus standard treatment of air leakage after pulmonary lobectomy. Eur J Cardiothorac Surg. 2010 Dec;38(6):683-9.
9 Tsubokawa N, Miyata Y, Mimae T, Sasada S, Yoshiya T, Mimura T, et al. Histologic changes associated with the use of fibrinogen- and thrombin-impregnated collagen in the prevention of pulmonary air leakage. J Thorac Cardiovasc Surg. 2015 Apr;149(4):982-8.

10 Tanaka H, Fukushima K, Srinivasan PK, Pawlowsky K, Koegel B, Hata K, et al. Efficacy of the novel medical adhesive, MAR-VIVO-107, in an acute porcine liver resection model. Surg Innov. 2017 Oct;24(5):423-31.

11 Fukushima K, Tanaka H, Kadaba Srinivasan P, Pawlowsky K, Kögel B, Uemoto S, et al. Hemostatic efficacy and safety of the novel medical adhesive, MAR VIVO-107, in a rabbit liver resection model. Eur Surg Res. 2018; 59(1-2):48-57.

12 Srinivasan PK, Sperber V, Afify M, Tanaka H, Fukushima K, Kögel B, et al. Novel synthetic adhesive as an effective alternative to Fibrin based adhesives. World J Hepatol. 2017 Aug 28;9(24):1030-9.

13 Dargaville PA, Keszler M. Setting the ventilator in the NICU. Pediatr Neonat Mech Vent Basics Clin Pract. 2013 Oct 8:1101-25.

14 Baby PM, Jacob SS, Kumar R, Kumar P. An innovative approach for serial injection in marginal vein and blood collection from auricular artery in New Zealand white rabbit. MethodsX. 2017;4:457-60.

15 Mintz PD, Mayers L, Avery N, Flanagan HL, Burks SG, Spotnitz WD. Fibrin sealant: clinical use and the development of the University of Virginia Tissue Adhesive Center. Ann Clin Lab Sci. 2001 Jan;31(1):108-18.
16 Kober BJ, Scheule AM, Voth V, Deschner N, Schmid E, Ziemer G. Anaphylactic reaction after systemic application of aprotinin triggered by aprotinin-containing fibrin sealant. Anesth Analg. 2008 Aug;107(2):406-9.

17 Hino M, Ishiko O, Honda KI, Yamane T, Ohta K, Takubo T, et al. Transmission of symptomatic parvovirus B19 infection by fibrin sealant used during surgery. Br J Haematol. 2000 Jan;108(1):194-5.

18 Kawamura M, Sawafuji M, Watanabe M, Horinouchi H, Kobayashi K. Frequency of transmission of human parvovirus B19 infection by fibrin sealant used during thoracic surgery. Ann Thorac Surg. 2002 Apr;73(4): 1098-100.

19 Ferreira P, Silva AF, Pinto MI, Gil MH. Development of a biodegradable bioadhesive containing urethane groups. J Mater Sci Mater Med. 2008 Jan;19(1):111-20.

20 Heise D, Mirlas Y, Helmedag M, Eickhoff R, Kroh A, Lambertz A, et al. Two polyurethane adhesives for PVDF fixation show superior biocompatibility in a rat model. J Invest Surg. 2020:1-7.

21 Gika M, Kawamura M, Izumi Y, Kobayashi K. The short-term efficacy of fibrin glue combined with absorptive sheet material in visceral pleural defect repair. Interact Cardiovasc Thorac Surg. 2007 Feb;6(1):12-5.

22 Itano $\mathrm{H}$. The optimal technique for combined application of fibrin sealant and bioabsorbable felt against alveolar air leakage. Eur J Cardiothorac Surg. 2008;33(3):457-60. 